\section{Acute Pseudogout Following Intravenous Neridronate for Osteoporosis}

\section{To the Editor:}

An 84-year-old woman with a history of surgical menopause at the age of 37 years, gastroesophageal reflux disease, and prolonged corticosteroid use (prescribed by her general pratictioner for osteoarthritis-related pain), sustained a low-trauma vertebral fracture at L3 level. Radiographs showed previous L2 fracture. Other investigations were unremarkable, except for low $25-\mathrm{OH}$ vitamin D levels $(22.1 \mathrm{ng} / \mathrm{ml})$ and elevated plasma parathyroid hormone $(144 \mathrm{pg} / \mathrm{ml})$. She was then diagnosed with osteoporosis, supplemented with $300,000 \mathrm{IU}$ of oral cholecalciferol, and started therapy with neridronic acid (NA), $100 \mathrm{mg}$ intravenously ${ }^{1}$. Corticosteroids had been tapered before starting NA. The day after her first NA dose, she noticed polyarthralgia, myalgia, and fever (to $38^{\circ} \mathrm{C}$ ). Over the subsequent 5 days, symptoms eased, but she experienced progressive pain and swelling of her left shoulder. Pain was severe and she was unable to lift her left arm for activities of daily living. She came to observation 13 days after the infusion of NA. Her shoulder was still swollen, tender, and warm, and movements were still restricted.

She was systemically well, and standard laboratory investigations revealed slightly high C-reactive protein $(2.57 \mathrm{mg} / \mathrm{dl})$ and erythrocyte sedimentation rate $(48 \mathrm{~mm} / \mathrm{h})$. $25-\mathrm{OH}$ vitamin $\mathrm{D}$ was improved to normal levels $(30.4 \mathrm{ng} / \mathrm{ml})$ and parathyroid hormone decreased, although it was still higher than reference values $(92.5 \mathrm{pg} / \mathrm{ml})$. Plasma uric acid level was within the normal range $(4.5 \mathrm{mg} / \mathrm{dl})$.

Her left shoulder was then aspirated, and a yellow, turbid fluid was drawn. It was biochemically analyzed and sent for culture. Polarizing light optical microscopy revealed intracellular, rhomboid-shaped crystals, with slight birefringence, suggestive for calcium pyrophosphate dihydrate (CPPD) crystals. Synovial fluid examination revealed white blood cells $16,770 / \mathrm{mm}^{3}$ (89\% neutrophils), uric acid $4.6 \mathrm{mg} / \mathrm{dl}$, protein $4.9 \mathrm{~g} / \mathrm{dl}$, glucose $114 \mathrm{mg} / \mathrm{dl}$, lactate dehydrogenase $972 \mathrm{U} / \mathrm{l}$ (normal value 208-450). Synovial fluid culture was negative. She underwent radiographs of knees and shoulders, which were negative for chondrocalcinosis.

We stopped therapy with bisphosphonates, and started parathyroid hormone receptor agonist therapy, vitamin $\mathrm{D}$, calcium supplement, and $25 \mathrm{mg}$ indomethacin 3 times daily. After a week of treatment she was well. The pain, stiffness, and swelling of the shoulder disappeared, as did the systemic symptoms.

In this patient, a systemic inflammatory reaction, followed by acute CPPD arthritis, was associated with her first NA infusion. Synovial fluid analysis and clinical findings were consistent with the diagnosis of pseudogout. Even if calcium hydrogen phosphate crystal deposition had been considered in the differential diagnosis, early detection of birefringent crystals with optical microscopy suggested CPPD crystals, since brushite crystals are birefringent but rarely small and rhomboidal. Prompt antiinflammatory therapy resolved the pseudogout attack.

There are few reports of pseudogout following bisphosphonate treatment for osteoporosis and complex regional pain syndrome. Only 4 cases were reported: 1 with weekly alendronate ${ }^{2}, 1$ with etidronate ${ }^{3}$, and 2 with pamidronate ${ }^{4,5}$.

Aminobisphosphonates, such as NA, have been related to a systemic inflammatory response (which comprises fever, generalized illness, joint pain, and myalgia), probably because of accumulation of isopentenyl-pyrophosphate and subsequent activation of $\mathrm{V} \gamma 9 / \mathrm{V} \delta 2 \mathrm{~T}$ cells by $\mathrm{T}$ cell receptor, which in turn promotes copious production of tumor necrosis factor- $\alpha$ and interleukin $6^{6}$.

In contrast, the mechanism by which bisphosphonates can produce a pseudogout attack is unclear. We suggest that the NA could inhibit the resorption or breakdown of pyrophosphate in the articular space and indirectly support the persistence of these crystals in synovial fluid, contributing to the onset of pseudogout attack ${ }^{7}$. Another possible explanation is that NA can inhibit alkaline phosphatase activity and so could promote CPPD crystal formation, inhibiting dissolution and promoting acute pseudogut. However, both these interpretations remain speculative.

This is the first report of pseudogout after NA treatment. Although uncommon, physicians need to know about this side effect. Its diagnosis is based on a synovial fluid analysis.

STEFANO CARDA, MD; MARCO INVERNIZZI, MD, Physical and Rehabilitative Medicine, AUO Maggiore della Carità, Novara; PIER PAOLO SAINAGHI, MD, Department of Clinical and Experimental Medicine, University of Eastern Piedmont A. Avogadro, Novara, and Allergology and Immunology Unit, AUO; CARLO CISARI, MD, Physical and Rehabilitative Medicine, AUO; Department of Clinical and Experimental Medicine, University of Eastern Piedmont A. Avogadro; Rehabilitation Center Mons. L. Novarese, Moncrivello (VC), Italy. Address correspondence to Dr. S. Carda, Physical and Rehabilitative Medicine Department, AUO Maggiore della Carità, v. le Piazza d'Armi 1, 28100 Novara, Italy. E-mail: stefano.carda@virgilio.it

\section{REFERENCES}

1. Braga V, Gatti D, Colapietro F, Battaglia E, Righetti D, Prizzi R, et al. Intravenous intermittent neridronate in the treatment of postmenopausal osteoporosis. Bone 2003;33:342-5.

2. Young-Min SA, Herbert L, Dick M, Fordham J. Weekly alendronate-induced pseudogout. J Rheumatol 2005;44:131-2.

3. Watanabe H, Yamada S, Anayama S, Sato E, Maekawa S, Sugiyama $\mathrm{H}$, et al. Pseudogout attack induced during etidronate disodium therapy. Mod Rheumatol 2006;16:117-9.

4. Wendling D, Tisserand G, Griffond V, Saccomani C, Toussirot E. Acute pseudogout after pamidronate infusion. Clin Rheumatol 2008;27:1205-6.

5. Malnick SD, Ariel-Ronen S, Evron E, Sthoeger ZM. Acute pseudogout as a complication of pamidronate. Ann Pharmacother 1997:31:499-500

6. Hewitt RE, Lissina A, Green AE, Slay ES, Price DA, Sewell AK. The bisphosphonate acute phase response: Rapid and copious production of proinflammatory cytokines by peripheral blood $\gamma \delta \mathrm{T}$ cells in response to aminobisphosphonates is inhibited by statins. Clin Exp Immunol 2005;139:101-11.

7. Shinozaki T, Pritzker KP. Regulation of alkaline phosphatase: implications for calcium pyrophosphate dihydrate crystal dissolution and other alkaline phosphatase functions. J Rheumatol 1996;24:677-83.

J Rheumatol 2010;37;5; doi:10.3899/jrheum.091016 